\title{
Motherhood and fatherhood of patients with inflammatory rheumatic diseases in the era of biologics. Where are we after 20 years of anti-TNFs' use?
}

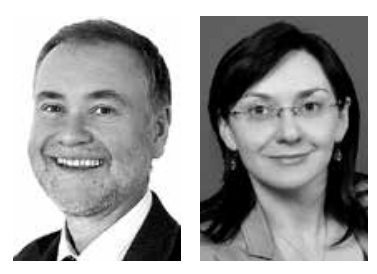

\author{
Robert J. Moots ${ }^{1,2}$, Anna Felis-Giemza ${ }^{3}$ \\ ${ }^{1}$ Department of Musculoskeletal Biology, Institute for Ageing and Chronic Disease, University of Liverpool, UK \\ ${ }^{2}$ Clinical Sciences Centre, Aintree University Hospital, Longmoor Lane, Liverpool, UK \\ ${ }^{3}$ Connective Tissue Disease Clinic, Institute of Rheumatology, Warsaw, Poland
}

Biologic therapies have revolutionised the treatment of inflammatory rheumatic diseases such as rheumatoid arthritis (RA), spondyloarthropathies (SpA) and psoriatic arthritis (PsA), enhancing not only outcomes but also patients' expectations. The most frequently used biologics in rheumatology currently are the anti-tumour necrosis factor agents (anti-TNFs), which have been used in routine care for nearly 20 years. The development of these drugs, alongside a treat-to-target strategy, now allows both physicians and patients to work together with the goal of inducing remission and raising quality of life to that of healthy people. Patients can now expect to work productively and enjoy their life in a manner hitherto unimaginable. We are concerned, however, that these huge advances have not yet been fully translated into effective management of fertility and pregnancy.

Current manufacturers' guidelines recommend that anti-TNFs should be discontinued prior to conception for periods ranging from 3 weeks for etanercept to 6 months for infliximab and golimumab [1]. In Poland, recommendations provided by the "Drug Program" are even more restrictive [2] and, we believe, in need of revision to deliver optimal evidence-based care.

The key goals are to maximise the opportunity for conception and produce the best outcomes for mother and baby. However, there is clearly an important balance to be made. Whilst optimising care pre-conception will minimise inflammatory disease (enhancing conception and helping maintain pregnancy), it is essential to avoid exposure of both mother and developing foetus to harm. In inflammatory arthritis, the most critical period in a planned pregnancy is the preconception period.
Withdrawal of drugs, whether biologics or disease-modifying anti-rheumatic drugs (DMARDs), during this time is highly likely to result in a flare, which in turn may reduce the chance of conception and risk an adverse pregnancy outcome. In the case of drugs with teratogenic properties, such as methotrexate (MTX) or leflunomide (LEF), ceasing therapy pre-conception is clearly essential. However, few other synthetic or biologic DMARDs appear to provide a real life risk. According to the US Food and Drug Administration (FDA), anti-TNFs, together with sulphasalazine (SSZ) and hydroxychloroquine, are only considered as category B (Table I).

During their 20 years of use in rheumatic diseases, a large body of evidence has emerged to suggest that continuation of anti-TNFs up to and perhaps even during pregnancy is not associated with either adverse pregnancy outcomes or congenital malformations compared to the general population. This evidence comes from many sources, including case series, systematic reviews, industry reports from surveillance programmes and, importantly, biologics registries.

The British Society for Rheumatology Biologics Registry (BSRBR) reported that of 130 pregnancies in patients with RA treated with anti-TNFs at the time of conception, there was a significantly increased risk of miscarriage only when these drugs were combined with MTX or LEF, compared to monotherapy with anti-TNF alone [3]. The risk therefore appeared to come from DMARDs rather than biologics. Anti-TNFs are large proteins (> 100 $\mathrm{kDa}$ ), and therefore simple diffusion across the placenta is unlikely to occur. However, active transport related via Fc receptors on trophoblasts begins to develop around 
Table I. US Food and Drug Administration categories for drug safety during pregnancy (FDA. Federal Register/Vol. 73, No. 104/2008)

\begin{tabular}{|c|c|}
\hline FDA category & \multicolumn{1}{c|}{ Description } \\
\hline A & $\begin{array}{l}\text { Adequate and well-controlled studies have failed to demonstrate a risk to the fetus during the first trimester } \\
\text { of pregnancy (and there is no evidence of risk in later trimesters). }\end{array}$ \\
\hline B & $\begin{array}{l}\text { Animal reproduction studies have not demonstrated a fetal risk, but there are no adequate and well-controlled } \\
\text { studies in pregnant women; OR animal reproduction studies have shown an adverse effect, but adequate } \\
\text { and well-controlled studies in pregnant women have failed to demonstrate a risk to the fetus during the first } \\
\text { trimester of pregnancy (and there is no evidence of a risk in later trimesters). }\end{array}$ \\
\hline C & $\begin{array}{l}\text { Animal reproduction studies have shown an adverse effect on the fetus, there are no adequate and well-con- } \\
\text { trolled studies in humans, and the benefits from the use of the drug in pregnant women may be acceptable } \\
\text { despite its potential risks; OR there are no animal reproduction studies and no adequate and well-controlled } \\
\text { studies in humans. }\end{array}$ \\
\hline There is positive evidence of human fetal risk based on adverse reaction data from investigational or market- \\
ing experience or studies in humans, but the potential benefits from the use of the drug in pregnant women \\
may be acceptable despite its potential risks.
\end{tabular}

the start of the second trimester of pregnancy and rapidly increases over the third trimester. Therefore most anti-TNFs can cross the placenta during the second and third trimester [4], and we believe that they are best avoided if possible during this period except to control the most severe cases, where on balance there may be a greater risk to the pregnancy of uncontrolled inflammation. In these circumstances, there is a good case to consider certolizumab, which, lacking an Fc fragment, is unlikely to cross the placenta and has been reported to be used successfully in this situation in inflammatory bowel disease (IBD) [5]. Indeed, rheumatologists can learn from the extensive experience with anti-TNF therapy during pregnancy in IBD. Disease activity in this condition is less suppressed by pregnancy, and flares during pregnancy carry a high risk of adverse birth outcomes, including congenital abnormalities.

The 2010 European Crohn's and Colitis Organisation (ECCO) guidelines state that 'medical treatment for Crohn's disease (except methotrexate) should be generally continued during pregnancy, because the benefits outweigh the risk of medication' use $[6,7]$.

After delivery, different issues arise. As they are immunoglobulins, anti-TNFs can pass into human breast milk. A decision must therefore be made whether to avoid breast-feeding or discontinue anti-TNF therapy, taking into account the balance of benefit of breast-feeding for the child and the need for adequate therapy for the mother.

Finally, what about men on anti-TNFs who want to become fathers? The teratogenic effect of MTX is well known (even at low doses). Therefore, correctly, it is suggested that the washout period in men should be 3 months before conception, as in women. But should anti-TNFs be stopped when men are planning a family?

This question is very important, not least because we observe that clinical improvement and increased quality of life are typically associated with subsequent improvement of libido. Reassuringly, manufacturers' guidelines do not include the requirement for male contraception during anti-TNF treatment. Whilst there is limited evidence about anti-TNF use in men with inflammatory rheumatic diseases, exposure of men to these drugs around conception does not appear to be associated with any adverse pregnancy outcomes [8-10]. Although infertility is more frequently observed in both men and women with rheumatic diseases, there are no reports of male-related infertility in relation to anti-TNF therapies in RA [11], yet one series has reported asthenozoospermia in two of four men with SpA receiving infliximab [12].

In contrast, some reports indicate that anti-TNF therapy in men with SpA could actually improve sperm motility and vitality in comparison to untreated patients with no difference in sperm quality between SpA patients treated with anti-TNFs and healthy controls [13].

As rheumatologists, we have come a long way in delivering better treatments, which greatly benefit our patients. However, we fear that a defensive, conservative approach in withholding biologics before concep- 
tion and, when required, also in pregnancy - whilst well intentioned - is not evidence based and sadly results in our patients being let down.

Surely it is now time for this to change!

The authors declare no conflict of interest.

\section{References}

1. http://www.ema.europa.eu/

2. Leczenie reumatoidalnego zapalenia stawów i młodzieńczego idiopatycznego zapalenia stawów. http://www.mz.gov.pl/leki/ refundacja/programy-lekowe

3. Verstappen SM, King Y, Watson KD, et al. Anti-TNF therapies and pregnancy: outcome of 130 pregnancies in the British Society for Rheumatology Biologics Register. Ann Rheum Dis 2011; 70: 823-826.

4. Simister NE. Placental transport of immunoglobulin G. Vaccine 2003; 21: 3365-3369.

5. Oussalah A, Bigard MA, Peyrin-Biroulet L. Certolizumab use in pregnancy. Gut 2009; 58: 608.

6. Hazes JM, Coulie PG, Geenen V, et al. Rheumatoid arthritis and pregnancy: evolution of disease activity and pathophysiological considerations for drug use. Rheumatology 2011; 50: 1955-1968.

7. Van Assche G, Dignass A, Reinisch W, et al. The second European evidence-based concensus on the diagnosis and management of Crohn's disease: special situations. J Crohns Colitis 2010; 4: 63-101.

8. Saougou I, Markatseli TE, Papagoras C, et al. Fertility in male patients with seronegative spondyloarthropathies treated with infliximab. Joint Bone Spine 2013; 80: 34-37.

9. Katz JA, Antoni C, Keenan GF, et al. Outcome of pregnancy in women receiving infliximab for the treatment of Crohn's disease and rheumatoid arthritis. Am J Gastroenterol 2004; 99: 2385-2392.

10. Clowse $M$, Wolf DC, Stach C, et al. Outcomes of pregnancy in subjects exposed to certolizumab pegol [abstract 1643]. Arthritis Rheum 2012; 64 (Suppl): S702.

11. Crazzolara S, Wunder D, Nägeli E, et al. Semen parameters in a fertile Swiss population. Swiss Med Wkly 2007; 137: 166-172.

12. Montagna GL, Malesci D, Buono R, Valentini G. Asthenoazoospermia in patients receiving anti-TNFs agents. Ann Rheum Dis 2005; 64: 1667.

13. Villiger PM, Caliezi G, Cottin V, et al. Effects of TNF antagonists on sperm characteristics in patients with spondyloarthritis. Ann Rheum Dis 2010; 69: 1842-1844. 